\title{
Small And Medium Scale Enterprises (SMEs) And Nigeria's Economic Development
}

\author{
Etuk, Reuben Ufot \\ Centre For Educational Development And Carrer Initiative, Calabar, Cross River State, Nigeria \\ Email:reuben_etuk@yahoo.com
}

Etuk, Grace Reuben

Department Of Sociology, University Of Calabar, P.M.B. 1115, Calabar, Cross River State, Nigeria

Email:graycetuk@yahoo.com

\section{Baghebo Michael}

Department Of Economics, Niger Delta University, Wilberforce Island, Bayelsa State, Nigeria Email:mikephd3c@gmail.com

\section{Doi:10.5901/mjss.2014.v5n7p656}

\section{Abstract}

In a developing country like Nigeria, there several socio-economic conditions impeding meaningful development, despite many interventions and policy strategies. However, Small and Medium Scaled Enterprises (SMEs), if fully developed have been identified as being beneficial in alleviating poverty through wealth and job creation. This sector can benefit any government that develops it to the extent that it has the capacity to grow a country's GDP, generate taxes and other revenue, as well as assist in bringing stability in the polity of a country. The corporate world can also gain from the specialised goods and services of SMEs and the healthy market competitiveness it promotes, thus giving way for a strong private driven economic sector, with entrepreneurs springing up. In Nigeria, the prevailing economic and political conditions have not given room for SMEs to thrive, as evidenced in the challenges they are currently facing in the country. Despite these challenges, SMEs are associated with immense benefits which can be harnessed to better the Nigerian economy. This forms the subject of analysis in this paper.

Keywords: Small and Medium scale, Enterprises, Entrepreneurship, Nigerian Business Environment, Economic Development.

\section{Introduction}

In order to tackle global challenges impeding sustainable human development, world leaders came up with the Millennium Development Goals (MDGs) in 2000, were expected to be met by 2015. The first of these MDGs is "to eradicate extreme poverty and hunger". Consequent upon this, it became very pertinent for the nations of the world to create strong socio-economic structure that would serve the interests of majority of their citizenry, especially the poor. Since then, different countries have been working to raise the living standard of their citizens in order to achieve this goal, among other Millennium Development Goals.

With globalization and economic liberalization, global economic activities have significantly increased over the recent past, bringing about corresponding increase in global wealth, which is said to have almost doubled since 1990 (SNV/WBSCD, 2007). However, despite the improvement in global development interventions, and positive growth in economic activities around the world, many individuals in developing countries still live below the poverty line. Moreover, as globalization proceeds, developing countries and face major challenges in strengthening their human and institutional capacities to take advantage of trade and investment opportunities.

While the governments in developing countries are saddled with the burden of making policies in trade and investment areas, it is enterprises that are directly involved in trade and investment. Consequently, the way government, development partners and the private sector address barriers to trade and investment, has direct implications on the economic growth of these developing countries. Therefore the private sector development, which has the core competence for wealth creation (WBCSD, 2004) and to take advantage of global trade and investment opportunity, is considered to be vital to poverty alleviation. This is implicated thus: 
2 per day. Poverty remains a major challenge to sustainable development, environmental security, global stability and a truly global market. The key to poverty alleviation is economic growth that is inclusive and reaches the majority of the people. Improving the performance and sustainability of local entrepreneurs and small and medium enterprises (SMEs), which represent the backbone of global economic activity, can help achieve this type of growth" (SNV/WBCSD, 2007:1).

In view of the above, this paper x-ray's economic implication of small and medium enterprises (SMEs) in developing countries with emphasis on the Nigerian business environment.

\section{Conceptualizing Small and Medium Scale Enterprises}

The notion of small and medium enterprises (SME) was introduced into the development landscape as early as the late 1940s, and the primary aim was to improve trade and industrialization in the present developed nations. (OECD, 2004). The definitions of SME are usually derived in each country, based on the role of SME in the economy, policies and programs designed by particular agencies or institutions empowered to develop SME. For instance, a small business in the developed economies of countries like Japan, Germany and United States of America (USA), may be a medium or large-scaled business in a developing economy like Nigeria. Moreover, the definition of SME also varies overtime from agencies or developing institutions to another, depending on their policy focus.

The above variation notwithstanding, SME can be defined based on certain criteria including, turnover, number of employees, profit, capital employed, available finance, market share and relative size within the industry. The definition can be based on either some quantitative or qualitative variables. Quantitative definitions mainly express the size of enterprises, mainly in monetary terms such as turnover, asset value, profit, as well as quantitative index like number of employees. As examples, the 1975 companies Act in the United Kingdom stated that an enterprise with a turnover of less than $£ 1.4$ million was small, those with turnover between $£ 1.4$ and $£ 5.7$ million were medium, while those enterprises having turnover above £5.7 million were large. It also went further to classify the enterprises based on number of employees - those with fewer than 50 workers being small, between 50 and 250 workers being medium and those employing above 250 workers were described as being large. Similarly, the European Union (EU) in 1995, defined SME as any enterprise employing less than 250 employees, and went further to break down the SME into micro (less than 10 employees, small (from 10 to 49 employees) and medium (between 50 to 249 employees).

In Nigeria, the National Council of Industry, 2003 categorized enterprises based on three criteria:

\begin{tabular}{|l|c|l|}
\hline \multicolumn{1}{|c|}{ Size } & No. Of Employees & $\begin{array}{c}\text { Total Cost Including Working } \\
\text { Capital But Excluding Land }\end{array}$ \\
\hline Micro & $1-10$ & Less than 1 Million \\
\hline Small & $11-35$ & 1Million - less than 40Million \\
\hline Medium & $36-100$ & 40Million - less than 200Million \\
\hline Large & 101 and Above & 200Million and Above \\
\hline
\end{tabular}

However, the asset base criterion is more commonly used in Nigeria. The Central Bank of Nigeria, in its 2005 guideline on Small and Medium Enterprise Investment Scheme (SMEIS), described SME as any enterprise with a maximum asset base of 200million naira ( excluding land and working capital) with no lower or upper limit of staff.

Using quantitative indices alone to define SMEs have proven unsatisfactory in many respects. This is because such indices are characterised by periodic alterations due to inflation and thus can sometimes be misleading. Noteworthy is the point that the CBN's definition of SME above may not accommodate many small businesses in Nigeria, which may be known as micro-enterprises. Also misleading is the fact that some enterprise may be labour intensive and so may be large in terms of number of workers employed, while on the other hand, a capital intensive firm may be large in terms of asset base but have fewer employees. And since all i.e. both small and big firms may incur losses, profit is therefore not a preferred yard stick for categorizing small and medium enterprises.

For the above limitation of quantitative definitions, a qualitative definition based on pre-determined characteristics of SME is needful, although not considered in the scope of this work.

The SME sector comprises very different types of businesses across a wide range of economic sectors. There are essentially two categories: those that are growth-oriented, and those small and micro enterprises that operate at the subsistence level to provide employment and income mainly for their owners and a relatively small number of external employees. Subsistence enterprises represent the vast majority of SMEs in developing countries. On the other hand, the growth-oriented type are innovative type of businesses which usually operate in growing markets, as well as businesses that are efficiency-oriented and/or network-intensive, which tend to grow through acquisitions. 


\section{Small and Medium Scale Enterprises versus Entrepreneurship}

The term 'entrepreneurship' is quite different small and medium enterprises (SME). Entrepreneurship is used to describe to creative, innovative, risk taking and organizational process and functions of individuals who initiate, run and nurture a business venture. It involves of identifying opportunities, creating or improving a new or existing technologies, products or services, bearing the accompanied risk and receiving resultant rewards.

Drucker, (1985) in his work, 'Entrepreneurship and Innovation', explained how entrepreneurship is different from SME. Entrepreneurship, according to Drucker, is all about creating a new thing, with added value and it involves a great deal of innovation. This invariably means not every new or small business can be said to be entrepreneurial. To be entrepreneurial, a business must apply unique management concepts and techniques. Also, products are developed and standardized, and process and tools are designed based on training analysis of work to be done. The process also involves the setting of required standards and controls; and creating new demands, a market and customers. Thus, an entrepreneur may start as a small and medium enterprise, he may not remain in that category for long, but all small and medium enterprise owners are not necessarily entrepreneurs.

\section{Small and Medium Scale Enterprises and the Nigerian Business Environment}

The development of viable SMEs in Nigeria has over the years been challenged by a number of harsh economic conditions which characterise the Nigerian business environment. Some of these challenges have been outlined by the Institute of Development Administrator of Nigeria (IDAN, 2007).

First, informal sources of finance still remain the major source of funding for SMEs in Nigeria. These include personal saving and borrowing from friends, families and credit associations. Formal financial institutions like commercial banks are still very unwilling to grant credits to SMEs. On the other hand micro finance schemes and institutions are still in developing stages and so can only do little.

Secondly, the success of economic ventures like SMEs depends largely on the entrepreneurial skills. SME operators must possess the capacity to manage and acquire basic skill of planning, organizing, coordinating, leadership and communication. Creative and innovative abilities are gotten through work experience in other enterprises or through technical and managerial training schemes. However, for SMEs in Nigeria high failure rate is usually recorded due to poor managerial and entrepreneurial skills necessary for the achievement of results.

Thirdly, there is the challenge of inadequate Infrastructural and Institutional Support: Weak infrastructural facilities such as electricity, portable water, feeder roads, etc. are the still the bane of SME growth in Nigeria. Also, State institutions like the Police, the Judiciary and others are still not strong enough in providing internal security and fast justice. Besides, there is no adequate protection of intellectual property. Furthermore, registration fees for some products in some government agencies are still the same for the small and large firms, irrespective of resource availability. Above all, both small and large firms pay the same minimum amount in opening corporate account in many banks.

Fourthly, incessant political conflicts, ethno-religious conflicts, as well as poor governance and accountability in public service, have all functioned to make the Nigerian business environment shaky and unreliable.

Other unfavourable conditions include: flabby fiscal and monetary measures, multiple taxation, poor implementation of high interest rate and unstable foreign exchange as well as high inflation rates. These have weakened the economy and expose it to the vagaries of international capitalist system. The consequences have been overdependence on foreign technologies, final product and values, and dilapidated infrastructure. These conditions make the small firms i.e. SMEs, major victims, so that not only are their competitive abilities reduced, their mere existence becomes a struggle.

In addition to the above, are challenges confronting entrepreneurship in Nigeria, which also indirectly affect SMEs, due to the relationship existing between SMEs and entrepreneurship For instance, a number small businesses remain small for years because of the mind-set of their owners, i.e. poor entrepreneurial spirit. In Nigeria, many are in business not for the passion but just to meet their daily needs. They lack the basic knowledge of managing their venture beyond the subsistence level. As such, there is no innovation and this affects their global competitiveness. Also, the economic system in Nigeria is majorly good at producing contractors who parasite on government jobs, and middle men who flourish in informal business sector. Besides, the concept of entrepreneurship is generally reduced to individuals seeking profit through supernatural and superstitious means rather than through strategic management process. All these as noted in Ogbor and Ikhimokpa (2005), are the result of lack of entrepreneurial education.

Furthermore in Enwegbara (2006), it is the organic process of economic development also requires the education of young persons in job-enhancing education such as science, engineering and technology. These are needed to support 
the entrepreneurial potential and jumpstart the national economy. Where these trained individuals are not sufficiently deployed, they migrate to other countries with the right enabling environment. They formed the so called successful African in Diaspora contributing enormously to the economic development of these countries and thus the continue decrease of indigenous African entrepreneur in the continent.

Even when they come back to invest in Africa with burning desire of acquainting younger ones with the entrepreneurial spirit, spread their talent, knowledge, experience, the prevailing enabling political, ethical, economic, infrastructural, etc., environment is discouraging, making them to be employees of the state and producers of raw materials purely for export and import of finished goods from the west. This stated Enwegbara (2006) has had tremendous negative effect on African economic development for a long time.

\section{Economic Implications of SME Development: The Case of Nigeria}

SMEs account for a large proportion of the total employment growth many countries. In such countries, SMEs produce a significant share of their increases in Gross Domestic Product (GDP), while the contributions of larger enterprises tend to remain stable (ADB 2002). For instance, in the OECD economies, SMEs and micro enterprises account for over $95 \%$ of firms, $60-70 \%$ of employment, $55 \%$ of GDP and generate the lion's share of new employment. In the case of developing economies, the situation is not very different. For instance, in Morocco, $93 \%$ of firms are SMEs and account for $38 \%$ of production, 33\% investment, 30\% export and 46\% employment. Similarly, in Bangladesh, enterprises of less than 100 employees account for $99 \%$ of all firms and $58 \%$ employment. Also, in Ecuador, $99 \%$ of all private companies have less than 50 employees and account for $55 \%$ of employment.

In the case of Nigeria, well-managed and healthy SMEs constitute significant sources of employment opportunities and wealth creation. While the citizens benefit in terms of employment and income, Government also benefits by generating revenue in form of taxes. This can be a strong factor to social stability. It is noteworthy that not all SMEs and microenterprises are in the formal sector; some of them occupy the unofficial labour market, which varies in size from an estimated $4-6 \%$ in developed countries to over $50 \%$ in developing nations. According to the International Finance Corporation (IFC, 2006), there is a positive relationship between a country's overall level of income and the number of SMEs per 1,000 people. The World Bank's Doing Business reports indicate that a healthy SME sector corresponds with a reduced level of informal or "black market" activities. Thus, managing SME sector to reduce the number of informal business is essential in the Nigerian development project.

SMEs are regarded as the bedrock of industrialization. Because a number of them possess extensive knowledge of resources, as well as demand and supply trends, they constitute the chief supplier of input to larger firms. They also serve as the main customers to the larger firms; provide all sorts of products ranging from food, clothing, recreation, entertainment, healthcare, education, and so forth. They help in economic development through industrial disposal and production of primary and intermediate products. They can also supply the material needs of the larger enterprises. In addition, they provide specialized, and many times, personal services. In summary, SMEs constitute important sources of local supply and service provision to larger corporations.

Developing countries represent a huge, largely untapped market for large corporations. By working closely with SMEs, large corporations can develop new customer base that may not be accessible to the traditional distribution networks of these corporations.

SMEs also represent important sources of innovation. They tend to occupy specialized market "niches" and follow competitive strategies that set them apart from other companies. This might include re-engineering products or services to meet market demands, exploring innovative distribution or sales techniques, or developing new and untapped markets. This often makes them good partners for large corporations.

In the financial sector, emerging economies represent a huge potential market for credit, particularly in subSaharan Africa, where according to the United Nations Capital Development Fund (UNCDF), only 4\% of Africans have a bank account. Local financial institutions that have successfully served the SME market in developed countries have found it highly profitable, according to United Nations Conference on Trade and Development (UNCTAD, 2001). Large international banking groups are beginning to tap into these markets. For instance, today Barclays Bank is present in 12 African countries, employs 41,000 people - one-third of its total workforce - and has 8 million customers. Africa accounts for $13 \%$ of the group's profits. Barclays has worked to integrate SMEs into its operations. In their efforts to localize value creation, many large companies in the world increasingly rely on local companies as a crucial component of their value chain. Furthermore, SMEs help in the development of local technology and mobilization and utilization of domestic savings. Thus, increases in SME efficiency can also improve the competitiveness of larger firms that depend on SME suppliers, and therefore improve the competitive position of a country's economy 
SMEs tend to be more labour intensive than larger firms, and capital requirements for establishing them are low. This widens the chances of many individual to participate in them and by so doing contribute to industrial development. Moreover, the size and structure of SMEs give them flexibility in management approaches which make them respond swiftly to changes and adapt to market needs much more quickly than their large enterprise counterparts in comparable industries. Thus in these days of increased emphasis on private-sector-driven economy, SMEs act as engines of the much desired private-sector-led economic growth and diversification.

The development of many small and private enterprises with the associated market competition spur up entrepreneur spirit in many SMEs. This will in turn have significant impact on economic development. This is because entrepreneurship is a vital factor in economic development and social change, since it makes for continuous innovation, and commercialization of innovation and technology. Entrepreneurs are proactive to change. They like competition and are always ahead in the market place. They are change agents and catalyst for transforming resources into new products and services with greater utility and value. All these immensely impact on economic development and growth.

Poverty is a major threat to attaining sustainable human and environmental development, as well as the much needed global economic and socio-political stability (SNV \& WBSCD, 2007). However, one of the keys to poverty alleviation is an economic growth that is inclusive and reaches majority of the people. According to Sen (2000), the basic thrust of development is to enlarge people's choices and to create an enabling environment for people to enjoy better standard of living. This can be achieved by improving the performance and sustainability of entrepreneurs and small and medium enterprises, as a backbone to economic activities. Poverty can then be reduced since subsistence enterprises are said to represent the vast majority of SMEs in developing countries. They are known to typically account for more than $90 \%$ of all firms outside the agricultural sector - with majority of them being essentially micro-enterprises, employing family members and close relatives. As such, the development of SMEs can be a key instrument in poverty reduction efforts of Nigerian government. Poverty can be reduced directly through their contribution to economic growth, employment and income generation.

Furthermore, SMEs often have a vested interest in community development. Being local, they rely upon communities for their workforce. For the communities, they provide goods and services tailored to local needs and at costs affordable to local people. They are an important source of employment, particularly for low-skilled workers, as well as women and young people, who usually make up the greatest proportion of the unemployed in emerging economies. Their flat management structures mean that their personnel must fulfil multiple roles, which makes them less vulnerable to unemployment during periods of economic downturn. Their small size and flexibility allow them to adjust to local market fluctuations and to weather local market shocks more comfortably. If well established in rural communities, migration to urban centre is often reduced, thus reducing excessive pressure on urban infrastructure.

\section{Towards Building a Formidable Small and Medium Scale Enterprises in Nigeria}

For SMEs to thrive, favourable institutional frameworks are required. Unfortunately, their needs are often overlooked by policy-makers and legislators, who tend to target larger corporations. Also, they are usually left out when it comes to tax incentives or business subsidies. They suffer more than big companies from the large burden and cost of bureaucracy, (World Bank, 2006). Only few SMEs possess the necessary financial or human resources to deal with these. Therefore, government can assist SMEs by:

Implementing inclusive reforms. Governments need to create the necessary enabling frameworks and relax the burden of regulatory measures. Additionally, they can simplify business registration procedures and paperwork to make them cheaper, simpler and speedier. A World Bank report stated that reform expands the reach of regulation by bringing businesses and employees into the formal sector." The same report also concludes that the greater a country's ease of doing business, the greater the number of jobs created in the formal sector "because the benefits of being formal (such as easier access to credit and better utility services) often outweigh the costs (such as taxes)." Most importantly, efforts must be strengthened to tackle corruption

Providing financial and tax incentives: To encourage SMEs to join the formal sector, governments need to provide tax incentives for SMEs and subsidies similar to those available to large corporations or micro-entrepreneurs, as well as make provisions for start-up funds for SMEs.

Encouraging friendly regulatory environments: Governments should promote public-private partnerships to attract venture capital funds and higher levels of investment, and put in place measures to create investor-friendly environments. Big corporations and potential investors need guarantees that their investments and infrastructure are not going to be expropriated.

Involving business in identifying necessary reforms: Increasingly, the business voice is being listened to in 
decisions aimed at effecting change. In several countries, such as Mali and Mozambique, private businesses now participate in identifying the most needed reforms. The culture of bureaucrats telling bureaucrats what's good for business is gradually disappearing.

Export potential: SMEs contribute a large share of manufactured exports in most industrialized East Asian economies like China and India, ranging from $31-56 \%$, than less developed African economies of less than $1 \%$ in Tanzania and Malawi, for instance. There is therefore the need to focus on policies that will promote the SMEs export potential to boost economic growth and development.

Apart from government, large corporations can also support the development of a strong and reliable SME sector by:

i. $\quad$ Building supply chain capacity: The many large corporations that source their supplies from developing countries require reliable suppliers. Large corporations can help SMEs become more viable business partners by providing training in basic skills such as management, bookkeeping, business planning, marketing, distribution, and quality control. They can assist through technology transfers, direct investment in infrastructure, and the sharing of knowledge. These make SMEs more competitive, as well as facilitate their access to credit. All of this can benefit the large corporations by creating more effective and inclusive supply chains.

ii. Rationalizing procurement procedures: Many global companies use intermediaries to identify local suppliers. This can add an extra layer of cost to the operation, a financial outlay that rarely goes to the originator of the goods. It also adds time. By building relationships with SMEs, large corporations can cut out the middlemen. This helps drive down costs, hastens delivery and improves quality.

iii. Strengthening local distribution networks: SMEs have local knowledge, understand domestic consumer demands, and have access to remote regions. By contracting local SMEs to sell and distribute their products in these markets, large corporations can help strengthen the sales capacity and income of local SMEs. At the same time, they can strengthen their own distribution networks and open up new markets for their products.

iv. Improving standards: Global companies are frequently asked about the operations of their suppliers, and thus can offer transparency along their supply chains. Large corporations can help their SME suppliers to comply with international standards such as ISO 14001. Such compliance can enable SMEs to compete in international markets while at the same time improving the overall quality of suppliers to large corporations.

v. Improving environmental performance: Collectively SMEs have considerable environmental impact. However, given the various challenges with which they are confronted, and the perception that their individual impact is not significant, it is unlikely that environmental concerns will figure high on their business agenda. By engaging with SMEs, assisting them with capacity building, and aiding them with compliance, particularly with environmental standards, large corporations can help SMEs integrate sustainable development thinking into their production processes and operations.

vi. Providing access to financial services

SMEs require greater access to financial services and investment capital. Large corporations have little difficulty securing sizeable bank loans and private investments. At the same time, microfinance, consisting of very small loans, tends to benefit individual entrepreneurs. SMEs fall in between and often struggle to obtain credit and loans, so that personal savings forms the major source of funding for most of them throughout much of the developing world. Many financial institutions in these developing societies are reluctant to fund SMEs because of perceived risks, high transaction costs and similar challenges. Thus loans to SMEs, when they are able to obtain them, tend to carry higher interest rates and shorter pay-back times. However things may be changing. Many large banks are now partnering with development agencies and NGOs to serve the SME market.

\section{Recommendations and Conclusion}

Given the emphasis on, and the increasing number of SMEs in Nigeria, there is need to take stock of the state of SME development in the country and review the effectiveness of existing policies and institutional framework, with the aim of developing guidelines for future utilization in this sector.

There should be a shift to promote SME development by creating an enabling policy environment, which fosters SME competitiveness and reduces the transaction costs for smaller companies. It is important to pay attention to the fact that the removal of regulatory and administrative barriers is expected to encourage enterprises operating in the informal economy to formalize their structures, which is a pre-condition for expanding their operations. 
Furthermore, it necessary to shift from the supply-driven strategy (SDS) where subsidized and direct credit are implemented through various finance institutions, to a market-driven strategy (MDS), an approach that utilizes commercially driven allocation mechanism to promote SMEs. The SDS is generally not encouraged anymore because of their distorting effects and lack of financial sustainability. There should be measures to facilitate commercial bank lending to SMEs; like tackling inherent collateral and information problems and introducing improved lending policies, systems and procedures for SME clients, credit scoring modes, credit information services, and credit guarantee fund that minimize moral hazard by sharing risks with banks. Leasing can be used as a mechanism for addressing smaller businesses' lack of collateral. A few SMEs with high return on capital can also be supported with venture capital funds.

Additionally, there should be a business development services (BDS) models evolved from the direct provision of (usually subsidized) services by a fully public funded intermediary organization in line with determined priorities, to demand-oriented approaches as exemplified by voucher-based schemes which seek to be more responsive to SME needs while promoting BDS providers. In this case the SMEs may be expected to share at least some of the costs to encourage effective use.

Recent SME development concepts and management theories should be researched into, particularly those related to competitiveness clusters and supply-chain management, which are based on the economic benefits of interfirm cooperation. This will proffer ways to induce linkages among SMEs, or between SMEs and large enterprises that purchase their products and services.

SMEs have significant roles to play in the Nigerian economy, via generating employment for the teeming population of unemployed youths; alleviating poverty through incomes to poor household; participating in the global economy and partnering with larger corporations and so on. These roles of SMEs, as already discussed can further boost GDP and generate revenue to government through taxes and export potentials. In fact the benefits of SMEs are almost inexhaustive. However, several hurdles still stand in our way to achieving a formidable SME sector in Nigeria. The effort of all stakeholders namely: government, business/corporate citizens, individuals and the civil society are needed.

Lastly, given the growing interests in SME development, it is necessary to assess global experiences, identify successful approaches which can be adopted, develop a policy and practical guidelines for SME development, in order to harness the benefits SMEs can bring to the Nigerian economy.

\section{References}

ADB (2002). Technical Assistance for the Development of a Framework for SME Support. Asian Development Bank.

Drucker, P. (1985). Entrepreneurship and Innovation.

Enwegbara, O. B. (2006). Organic Process of Development and the African Entrepreneurship.

IDAN (2007). Entrepreneurship Management; Student study guide of the Institute of Development Administration of Nigeria (IDAN); Abuja.

IFC (2006). "Micro, Small and Medium Enterprise: A Collection of Published Data", in Newberry, Derek (2006). The Role of Small- and Medium-sized Enterprise in the Future of Emerging Economies. Earth Trends 2006. World Resources Institute under a Creative Common License.

Meyer-Stamer, J (1995). 'Micro-level Innovation and Competitiveness". World Development, Vol.23 pp. 143-148.

OECD (2004). Promoting Entrepreneurship And Innovative SMEs In A Global Economy: Towards a More Responsible and Inclusive Globalization. A Report of 2nd OECD Conference of Ministers Responsible for Small and Medium Sized Enterprise (SMEs) in Istanbul, Turkey (3-5 June, 2004).

Ogbor, J. and I. Ikhimokpa (2005). Conditions for Entrepreneurial Development

Sen, A. K. (1999). Development as Freedom. Clarendor Press; Oxford.

SNV/WBCSD (2007). "Promoting Small and Medium Enterprises for Sustainable Development". Development Focus; Issue Brief. World Business Council for Sustainable Development, Switzerland. www.wbcsd.org/web/development.htm

UNCTAD (2001). Reports on the Expert Meetings on Improving Competitiveness of SMEs in Developing Countries: The Role of Finance, including E-finance, to Enhance Enterprise Development. United Nation Council on Trade and Development.

World Bank (1990). World Development Report. Oxford University Press, N.Y.

World Bank (2006). Doing Business 2007: How to Reform. World Bank Report. 